Original article

https://www.journal-imab-bg.org

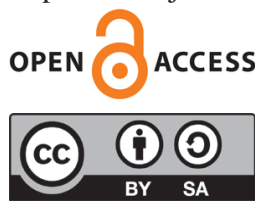

\title{
EPIDEMIOLOGY OF ALCOHOL INTOXICATIONS AMONG ADOLESCENTS IN VARNA REGION FOR 2015-2017 AND STUDY OF PARENT BEHAVIOR.
}

\author{
Snezha Zlateva ${ }^{1,2}$, Petko Marinov ${ }^{1,2}$, Georgi Bonchev ${ }^{1}$ \\ 1) Clinic for Intensive Treatment of Acute Intoxications and Toxicoallergies, \\ Naval Hospital - Varna, Military Medical Academy, Bulgaria \\ 2) Department of Pharmacology, Toxicology and Pharmacotherapy, Faculty of \\ Pharmacy, Medical University - Varna, Bulgaria.
}

\begin{abstract}
Purpose: To research the frequency of acute alcohol intoxications among young people of age 10-18 in Varna region within the time frame $2015-2017$ and to examine the correspondent parent behavior.

Material/Methods: A total of 159 adolescents were examined. All of them were registered patients of the Clinic for Intensive Treatment of Acute Intoxications and Toxicoallergies at the Naval Hospital - Varna. Alcohol dependence was studied by means of CAGE test. The evaluation of the parent behavior was done in accordance with Robert's methodology and involved 54 parents.

Results: It was demonstrated that the initial alcohol consumption age is very low, approximately 10-11. Acute alcohol intoxications among young people vary from year to year, but such cases were estimated to represent $12-19 \%$ of all registered alcohol intoxications in the region studied. Most abused beverage types are spirits and beer; wine is less preferred. The analysis of the parent behavior shows a definite underestimation of the problem in both sociological consequences and health risks directions.
\end{abstract}

Keywords: alcohol, adolescents, epidemiology, parent behavior, risks

\section{INTRODUCTION}

Alcohol consumption in Europe is highest compared to other continents. Adolescents are the target group of our attention, both because of the high frequency of alcohol use among young people and the scientific evidence of alcohol induced brain damage in the process of physical maturation leading to behavioral and social consequences. The use of spirits among young people in Europe is $3.2 \%$ of the fourteen-year-olds, $50.0 \%$ of the eighteen-year-olds and $80.3 \%$ of the secondary school graduates [1-4]. In the USA, $16 \%$ of incidental alcohol users are 12-17 years of age, and 10\% of them are considered a risky group [5]. The latest neurophysiological and neurochemical studies prove that the brain develops from childhood to the age of 25 , and through a number of plastic and dynamic processes, it specializes and improves its functions over this long period. The develop- ing brain is extremely sensitive to the effects of ethanol both due to accidental use (drinking, acute intoxication) and chronic use (dependence). A number of experimental data indicate an impairment of plasticity and brain functions, resulting in behavioral and cognitive deficits with serious social consequences [6].

The current epidemiological study presents the incidence of acute alcohol intoxications as well as the frequency of concomitant use of alcohol and drugs among adolescents (10-18) for the period January 2015 - October 2017 in Varna region, Bulgaria. The study is initiated by the Municipality of Varna, the Prevention Directorate and the Social Activities Directorate. Acute intoxications are one of the indicators on the basis of which the relevant decisions are made for our city and our region to prevent and restrict the distribution and use of alcohol and drugs, mainly aimed at teenagers.

\section{MATERIALS AND METHODS}

The subjects of the study were patients with acute alcohol intoxication, as well as a combination of alcohol and drugs, received for treatment at the Clinic for Intensive Treatment of Acute Intoxications and Toxicoallergies at the Naval Hospital - Varna for the period from January 2015 to October 2017. The sample was taken $100 \%$ from registered patients suffering acute intoxications based on hospital documentation and analytical toxicology reports of blood alcohol analysis. Patients are divided into two age groups: first 10-18 and second 19-64 (and older). To establish alcohol dependence in 12 juveniles ( 5 girls and 7 boys in 2017), a short CAGE test was used [7, 8]. To assess parent behavior, Robert's seven-stage crisis intervention model was used [9], thus covering 54 parents for 2017. Statistical processing was done by MS Excell ${ }^{\mathrm{TM}}$ using 2018 data for the population of Varna from the National Statistical Institute [10].

\section{RESULTS AND DISCUSSION}

The incidence of acute alcohol intoxication remained relatively constant for the period 2015-2017 with an average rate of approximately 80 cases to 100,000 citizens in Varna town. The variability was low: $81 / 100,000$ as of 2015 , 
$64 / 100,000$ as of 2016 , and $80 / 100,000$ as of 2017. (Table 1.) Our earlier study of the frequency of alcohol intoxications over a 25-year period (from 1991 to 2015) shows similar results [11]. The number of adolescents (10-18) with acute alcoholic intoxications compared to all acute intoxications for the relevant year in the region was $13.0 \%$ in $2015,12.2 \%$ in 2016 , and $19.1 \%$ in 2017 , which corresponds to a frequency between $9 / 100,000$ and 16/100,000 for the population of Varna town (Table 1). The average blood alcohol content for the adolescent group was found to be close to 2.0 $\% \circ\left(\mathrm{g} \mathrm{L}^{-1}\right)$.

Tabl. 1. Number and frequency of acute alcohol intoxications in age groups 10-18 and 19-64+ for 2015-2017.

\begin{tabular}{lccc}
\hline Type of intoxication & $\mathbf{2 0 1 5}$ & $\mathbf{2 0 1 6}$ & $\mathbf{2 0 1 7}$ \\
\hline Alcohol $(10-18)$ & $50(13.0 \%)$ & $37(12.2 \%)$ & $72(19.1 \%)$ \\
\hline Alcohol $\left(19-64^{+}\right)$ & 336 & 266 & 306 \\
\hline Alcohol (total) & 386 & 303 & 378 \\
\hline Alcohol + Drugs (10-18) & $2(3.4 \%)$ & $1(2.9 \%)$ & $0(0.0 \%)$ \\
\hline Alcohol + Drugs (19-64+) & 56 & 34 & 32 \\
\hline Alcohol + Drugs (total) & 58 & 35 & 32 \\
\hline
\end{tabular}

The concomitant use of alcohol and drugs is extremely dangerous to the health of adolescents due to their additive toxic effect, which may many times exceed the simple sum of the separate substances' toxicity. The incidence of acute combined alcohol and drug intoxication is presented on Table 1. In the group of adolescents (10-18), there were 2 cases in 2015 and one in 2016. Those cases were of combining alcohol with marijuana and alcohol with ecstasy.

The clinical symptoms of hospitalized adolescents were distributed as follows: psychomotor agitation $-7.4 \%$, somnolence $-44.5 \%$, sopor $-37.0 \%$, and coma $-11.1 \%$. The contrast between the relatively low alcohol blood content and the severe clinical conditions observed proves once again the substantial sensitivity of the central nervous system of adolescents to alcohol, which is a well-known fact [12].

The male-to-female ratio was different over the years. In 2015 and 2017, male acute intoxications prevailed with an average ratio value of $1.4: 1$, while in 2016 most often were female cases and a ratio value of $1: 1.7$. This fact deserves special attention, as it underlines the need for preventive measures specifically targeted at girls and young women. The female organism is more easily damaged by alcohol, more readily develops dependence, and after 5 years of abuse, damage taken appears much heavier compared to men. Worldwide, the frequency of alcohol dependence among women is roughly $1 \%$.

Early alcohol use is associated with a high risk to the health of minors. In the group studied, the youngest person was an 11-year-old patient with acute intoxication due to beer consumption, followed by 12-13-year-olds with brandy and yet older 14-year-olds with vodka and beer; vodka and whiskey; only with ouzo and only with vodka. Although there was no specific pattern in alcoholic beverage preference, spirits and beer are more common than wine. Usually, the process involved friends and preferred places were disco clubs, gardens (after school), and even during recesses. Most cases $(31 \%)$ occurred during the summer holidays (August). Acute intoxication concerns adolescents not only as an acute disturbance of consciousness that poses an imminent threat to their life but also as a possible risk of more significant consequences for the brain related to subsequent behavior. This is due to the fact that the adolescent brain, which is in a period of development of cognitive processes, gives individual achievements in this period, meaningful social expression and emotional impact. Ethanol has a negative impact on these learning processes, which has significant social implications both for the individual and for society [13].

A short CAGE test was conducted to determine alcohol dependence among adolescents hospitalized for acute intoxication treatment. This test has proven reliability; it has been approved for use in many European countries and includes four questions:

a. Reduction ("Have you ever considered reducing drinking?");

b. Critical annoyance ("Have you ever been upset of someone criticizing your way of drinking?");

c. Feeling guilty ("Have you ever felt bad or guilty because of drinking?");

d. Wake-up remedy ("Was there a case, the first thing to do in the morning is to take alcohol to wake you up, calm you down, or overcome a hangover?").

One positive answer raises doubts about dependence, and two positive responses are considered a certain sign of dependence. The CAGE test was conducted in 12 adolescents -5 girls and 7 boys in 2017. There were 4 respondents $(33 \%)$ that gave positive answers. One girl gave one positive answer; two girls gave two positive answers, and one boy gave one positive answer. This screening test showed that among the youth group alcohol intoxication is not always due to an isolated event, but as a result of systematic abuse in some cases. Although the 2017 test group is relatively small, the results are similar to our considerably larger earlier CAGE study of 448 students aged 16-17, and approximately $40 \%$ of respondents gave one or more positive answer. Therefore, one can conclude that drinking among students may be a chronic experience in about 30 $40 \%$ of the cases. This fact makes the discussion about the role of occasional alcohol abuse and their effects on the growing brain, especially actual and important. 
The traditional understanding is that ethanol intoxications among teenagers are incidental, and will diminish over time. Until recently, incidental alcohol abuse was considered only in the light of the immature liver enzyme system responsible for alcohol metabolism, as well as its adaptation (tolerance development) with gradually more frequent alcohol intake [12]. However, recent research suggests that repeated ethanol exposures in adolescents are critical to neuroanatomic and neurochemical development of the brain [14-18]. The brain is very sensitive to the effects of neurostimulator peptides, especially in the cortex and hippocampus, which occurs with repeated exposure to ethanol [19]. Ethanol and subsequent excessive excitability of neurons cause excitotoxic cell death [20,21]. Evidence of the deep and long-lasting effects of alcohol on neurophysiological brain function is objectively demonstrated in a number of multi-parameter studies such as event-related potential (ERP), EEG in awake and sleep mode, slow-wave sleep amplitudes (SWS). [22, 24-27].

To study parent behavior, we used Robert's method. There were 54 parents of teenagers with acute alcohol intoxication in 2017 involved in the study. Robert's sevenstage method is suitable for crisis intervention, such as the situation of parents whose children are hospitalized in an emergency, usually in a helpless state, sopor or coma. First, we look for a conversation with parents. Second, we aim to create a mutual trust during the crisis. Third, we try and identify the problem that concerns the life of the young person and research the possibility of systemic abuse or combining alcohol with drugs. Fourth, we help parents to cope with their feelings. Fifth, we offer alternative options for responding to cases of systemic abuse such as psychiatric care, psychologist counselling, systematic visits at the centers of the Municipality of Varna specialized in working with problem children. Sixth, we explain in detail the current medical procedures that are being taken. Seventh, if it is an alcohol/drugs dependence case, we plan their next steps together with them. The results showed a high level of anxiety in the parents $(76 \%)$ due to the intoxication and hospitalization of their child. Additionally, parents feel guilty about their children's behavior. Most often, they express disapproval of their behavior. In $80 \%$ of all cases, parents do not assess the risk of acute ethanol intoxication and are primarily interested in whether it is not "fake" alcohol or "methanol". Very often (24\%) the parents' first response is to deny the facts, to downplay what is happening and to blame others with the words "My child does not drink". In some of the cases (15\%), we found problematic families of one parent or a second marriage as well as adolescents cared for by grandparents. In almost all cases (92\%) there is a definite desire to finish or cancel treatment as quickly as possible and go home, with parents signing all hospital documents (early withdrawal statements). We noticed a few parents who came for their children in a seemingly intoxicated state, although such cases are rare $(2 \%)$. In one-third of all cases $(33 \%)$, parents did not know that children use alcohol outside the home in a systematic manner.

\section{CONCLUSION}

The incidence of acute intoxication among adolescent varies every year; however, it could be estimated to 12 $19 \%$ of all acute alcohol intoxications registered in Varna town. It equals approximately $9 / 100,000$ to $16 / 100,000$ for the population of Varna, although it should be taken in consideration that not all of the cases of acute alcohol intoxication are hospitalized. The age limit for initial alcohol use is very low, 10-11 years, and about $30 \%$ of cases concern systematic abuse. During the observed years, gender prevalence shows a uniform distribution with an alternating maleto-female ratio. Most often teenagers drink alcohol at parties, at disco clubs, in the park after school, even during school recesses, and especially during the summer break. Spirits and beer prevail to wine. There is a tendency for combining alcohol with drugs, mostly marijuana and ecstasy. Consultations with parents reveal an underestimation of the problem of drinking alcohol, which is expressed in the desire to quickly finish their treatment. The use of alcohol among adolescents is an underestimated risk factor for late personal and social problems. We are deeply convinced that the role of physicians in informing society about the risks of alcohol use during brain development from childhood to full maturation should be expanded.

\section{REFERENCES:}

1. Amodeo LR, Kneiber D, Wills DN, Ehlers CL. Alcohol drinking during adolescence increases consumptive responses to alcohol in adulthood in Wistar rats. Alcohol. 2017 Mar;59: 43-51. [PubMed]

2. Varlinskaya EI, Truxell E, Spear LP. Chronic intermittent ethanol exposure during adolescence: effects on social behavior and ethanol sensitivity in adulthood. Alcohol. 2014 Aug; 48(5):433-44. [PubMed]

3. Mooney SM, Varlinskaya EI. Enhanced sensitivity to socially facilitat- ing and anxiolytic effects of ethanol in adolescent Sprague Dawley rats following acute prenatal ethanol exposure. Alcohol. 2018 Jun;69:25-32. [PubMed]

4. Schindler AG, Tsutsui KT, Clark JJ. Chronic alcohol intake during adolescence, but not adulthood, promotes persistent deficits in risk-based decision making. Alcohol Clin Exp Res. 2014 Jun;38(6):1622-9. [PubMed]

5. Results from the 2007 National Survey on Drug Use and Health: National Findings. SAMHS. September
2008. [Internet]

6. Guerri C, Pascual M. Mechanisms involved in the neurotoxic, cognitive, and neurobehavioral effects of alcohol consumption during adolescence. Alcohol. 2010 Feb;44(1):15-26. [PubMed]

7. Mayfield D, McLeod G, Hall P. The CAGE questionnaire: validation of a new alcoholism screening instrument. Am J Psychiatry. 1974 Oct; 131(10):1121-3. [PubMed]

8. Ewing JA. Detecting alcoholism. The CAGE questionnaire. JAMA. 1984 
Oct 12;252(14):1905-7. [PubMed]

9. Roberts AR, Ottens AJ. The Seven-Stage Crisis Intervention Model: A Road Map to Goal Attainment, Problem Solving, and Crisis Resolution. Brief Treat Crisis Interv. 2005 Nov;5(4):329-39. [Crossref]

10. [Demographic statistics] [in Bulgarian] National Statistical Institute. Bulgaria. Annual statistics issue for Varna region. 2017. [Internet]

11. Marinov P, Zlateva S, Bonchev G, Sabeva Y, Bozov H, Yovcheva M, et al. [Acute alcohol intoxications - 25 years of experience.] [In Bulgarian] Aviation, Maritime and Space Medicine. 2017;1:6-9.

12. Seyffart G. Poison Index: The treatment of acute intoxication. Lengerich: Pabst Science Publishers. 1997. $671 \mathrm{p}$.

13. Dahl RE. Adolescent brain development: A period of vulnerabilities and opportunities. Keynote Address. In: Adolescent brain development: vulnerabilities and opportunities. Annals of The New York Academy of Sciences. 2004 Jun;1021(1):1-22. [Crossref]

14. Crews FT, Vetreno RP, Broadwater MA, Robinson DL. Adolescent alcohol exposure persistently impacts adult neurobiology and behavior. Pharmacol Rev. 2016 Oct; 68(4):1074-109. [PubMed]

15. Silveri MM. Contributions of GABA to alcohol responsivity during adolescence: Insights from preclinical and clinical studies. Pharmacol Ther.
2014 Aug;143(2):197-216. [PubMed]

16. Crews FT, Vetreno RP. Neuroimmune basis of alcoholic brain damage. Int Rev Neurobiol. 2014; 118 : 315-57. [PubMed]

17. Kyzar EJ, Floreani C, Teppen TL, Pandey SC. Adolescent alcohol exposure: burden of epigenetic reprogramming, synaptic remodeling, and adult psychopathology. Front $\mathrm{Neu}$ rosci. 2016;10:222. [PubMed]

18. Shnitko TA, Spear LP, Robinson DL. Adolescent binge-like alcohol alters sensitivity to acute alcohol effects on dopamine release in the nucleus accumbens of adult rats. Psychopharmacology (Berl). 2016 Feb; 233(3):361-71. [PubMed]

19. Johnston MV. Neurotransmitters and vulnerability of the developing brain. Brain Dev. 1995 SepOct;17(5):301-6. [PubMed]

20. Spear LP. Adolescent alcohol exposure: are there separable vulnerable periods within adolescence? Physiol Behav. 2015 Sep 1;148:12230. [PubMed]

21. Salling MC, Skelly MJ, Avegno E, Regan S, Zeric T, Nichols E, et al. Alcohol consumption during adolescence in a mouse model of binge drinking alters the intrinsic excitability and function of the prefrontal cortex through a reduction in the hyperpolarization-activated cation current. J Neurosci. 2018 Jul 4;38(27):620722. [PubMed]

22. Ehlers CL, Criado JR. Adolescent ethanol exposure: does it produce long-lasting electrophysiological effects? Alcohol. 2010 Feb;44(1):27-37. [PubMed]

23. Chandler LJ, Newsom $\mathrm{H}$, Sumners C, Crews F. Chronic ethanol exposure potentiates NMDA excitotoxicity in cerebral cortical neurons. $J$ Neurochem. 1993 Apr;60(4): 1578-81. [PubMed]

24. Niedermeyer E. Maturation of the EEG: development of waking and sleep patterns. In: Electroencephalography: Basic Principles, Clinical Applications, and Related Fields. Edited by Niedermeyer E, Lopes da Silva FH. 5th ed. Lippincott Williams and Wilkins. 2005. Chapter 11. p.209-234. [Internet]

25. Ohayon MM, Carskadon MA, Guilleminault C, Vitiello MV. Metaanalysis of quantitative sleep parameters from childhood to old age in healthy individuals: developing normative sleep values across the human lifespan. Sleep. 2004 Nov 1;27(7): 1255-73. [PubMed]

26. Porjesz B, Rangaswamy M, Kamarajan C, Jones KA, Padmanabhapillai A, Begleiter H. The utility of neurophysiological markers in the study of alcoholism. Clin Neurophysiol. 2005 May;116(5):993-1018. [PubMed]

27. Spear LP. Consequences of adolescent use of alcohol and other drugs: Studies using rodent models. Neurosci Biobehav Rev. 2016 Nov;70: 228-43. [PubMed]

Please cite this article as: Zlateva S, Marinov P, Bonchev G. Epidemiology of alcohol intoxications among adolescents in Varna region for 2015-2017 and study of parent behavior. J of IMAB. 2021 Jan-Mar;27(1):3502-3505.

DOI: https://doi.org/10.5272/jimab.2021271.3502

Received: 11/07/2019; Published online: 07/01/2021

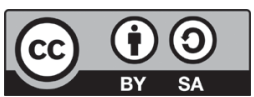

Address for correspondence:

Georgi Bonchev, PhD

Head, Laboratory of Analytical Toxicology, Military Medical Academy, Naval Hospital - Varna,

3, Hristo Smirnenski Str., 9010 Varna, Bulgaria.

E-mail: toxilab.varna@abv.bg, 